\title{
Literatura de viajes para la Honduras decimonónica: Visiones, invenciones e intervenciones. Representaciones, alteridad y contexto colonialista en exploraciones y aventuras en Honduras
}

Miguel Barahona ${ }^{1}$

\section{RESUMEN}

La literatura viajera contiene una función histórica documental y una doble articulación: la intimista y la egocéntrica como producto de la ideología del autor narrador; así, a partir de esta premisa se realiza un análisis del libro de William Vincent Wells (1982), Exploraciones y Aventuras en Honduras.

Con este estudio se intenta conceptualizar las diferentes percepciones del viajero con respecto a una sola realidad, pero enfocada desde las siguientes temáticas: las distintas percepciones de una realidad y los imaginarios e interpretaciones de la nación, desde el aspecto económico y social.

La literatura viajera contiene una función histórica documental y una doble articulación: la intimista y la egocéntrica como producto de la ideología del autor narrador; así, a partir de esta premisa se realiza un análisis del libro de Wells (1982).

Con este estudio se intentan conceptualizar las diferentes percepciones del viajero con respecto a una sola realidad, pero enfocada desde las siguientes temáticas: las distintas percepciones de una realidad y los imaginarios e interpretaciones de la nación, desde el aspecto económico y social.

En este estudio quedó evidenciado que en el libro de William V Wells, la historia y la literatura aportan datos para aproximarse a través de un estudio filológico a la sociedad en un determinado periodo de tiempo.

Palabras clave: imperialismo, intervencionismo, exploraciones, William V. Wells, imaginarios, viajeros por Honduras siglo XIX, viajes.

\footnotetext{
1 Universidad Nacional Autónoma de Honduras. Facultad de Humanidades y Artes, Escuela de Letras. Correo electrónico:mbarahona@unah.edu.hn
} 


\section{ABSTRACT}

Traveler literature includes a historical-documentary function and a double articulation: the intimate one and the self-centered one as a result of the ideology of the narrator author; thus, from this premise, an analysis about William Vincent Wells Book (1982) has carried out, Explorations and Adventures in Honduras.

This study, has tried to conceptualize the different perceptions of the traveler regarding to an alone reality but focused from the following subject matters: the distinct perceptions of a reality and the imaginaries and the country interpretations, from the economic and social aspect.

In this studio remains demonstrated that William V Wells's book, the history and literature provides data to approach through a philological study to the society in a certain period of time.

Keywords: imperialism, interventionism, scans, William V. Wells, imaginary, Honduras travelers nineteenth century, travels, and CentralAmerica.

"Lo primero que se reconoce es la pérdida de la patria...". Edward Said

\section{INTRODUCCIÓN}

Es preciso indicar que en este estudio de naturaleza ensayística el presupuesto fundamental se basa en que la literatura de viajes, ${ }^{2}$ con relación al autor-viajero, refleja una doble articulación: la íntima, desde la óptica de la descripción y la perspectiva universalista egocéntrica generada por el contacto cultural que tiene el autor-narrador al visitar nuevas regiones que le resultan exuberantes y desconocidas.

Y es que el viaje desde el punto de vista literario es un entramado recurrente donde

\footnotetext{
${ }^{2}$ En un artículo publicado en Istmo se hizo una apología sobre la literatura viajera donde se explica lo siguiente: "La literatura de viaje es un subgénero dentro de la narrativa que ha existido a lo largo de los siglos y que ha ido evolucionando. A través de este subgénero literario se puede conocer, desde variados puntos de vista, la geografía, la cultura y la historia de los países; así también la personalidad del autor en conjunto con los datos autobiográficos. El vínculo que existe entre el viaje y la aventura hace que esta literatura siempre haya sido recibida con beneplácito por el público lector en diferentes épocas. De esta forma las diferentes modas, sucesos históricos, descubrimientos de distintas culturas se daban a conocer desde el punto de vista del viajero" (Miguel Barahona, 2007).
} 
se sitúa al autor-narrador en una constante de espacio y tiempo, en el cual se va articulando una fascinación por lo descubierto, además de la descripción detallada de la sociedad visitada. ${ }^{3}$

En primera instancia se definirá la literatura de viaje, ya que esta tiene doble función, tal como lo indica Luis Alburquerque (2004: 504): "Función poética y función representativa muestran la cara y la cruz de la moneda en este género. Cuanto más nos acercamos hacia la primera, más palpable se hace su condición literaria y a la inversa, cuanto más nos aproximamos a la segunda, más se acentúa su carácter histórico y documental. En el filo de ambas funciones se desenvuelve este género que algunos han denominado, por esta razón, bifronte, cuya naturaleza ambigua lo ha llevado en ocasiones a ser desterrado del palenque literario".

Partiendo del supuesto de que la literatura viajera contiene una función histórica documental y una doble articulación: la intimista y la egocéntrica como producto de la ideología del autor- narrador, ${ }^{4}$ se realizó un análisis del libro de William Vincent Wells (1982), Exploraciones y Aventuras en Honduras. Este libro narra el periplo de un viajero norteamericano que en 1854 recorre el territorio hondureño, con una ruta que inicia desde el sur de la república, en dirección al este, precisamente hacia la región aurífera que se ubica en el departamento de Olancho.

A continuación se conceptualizan las diferentes percepciones del viajero con relación a una sola realidad, pero enfocada desde las siguientes temáticas:

1. Distintas percepciones de una realidad. Nada más propicio como el terreno discursivo a la hora de mostrar el perfil de las identidades en razón de contar con sus propias voces, pero desde la hegemonía del autor observador, el énfasis

\footnotetext{
${ }^{3}$ El viaje también es semejante a la creación de imágenes. Según Porter (1993), el viaje es crear paisajes sensuales y hermosos.

${ }^{4}$ En este apartado es bueno ver la otra cara de la moneda y considerar la propuesta de Edward Said, quien en su libro Cultura e Imperialismo parte de una convicción compartida según la cual todas las culturas tienden a construir representaciones de las culturas extranjeras colonizadoras para aprehenderlas de la mejor manera posible o controlarlas de algún modo. Asimismo, en este libro Said introduce la visión del otro, la visión ilustrada de los vencidos, entendiendo por tal la respuesta de intelectuales africanos, asiáticos, americanos y europeos a la dominación occidental, en lo esencial la anglofrancesa, que culmina con el gran movimiento de descolonización del llamado tercer mundo. La propuesta de Said se da en las relaciones de la cultura e imperialismo, la cual puede, sin duda, provocar reticencias de una época, como la nuestra, que desconfía de las cosmovisiones y, obviamente, ha habido críticas en ese sentido. Said se anticipaba a esas reticencias declarando su convicción de que es imposible abarcar en un solo libro todo el imperialismo y toda la cultura que el imperialismo occidental ha producido en relación directa o indirecta con las colonias. Él mismo se ha considerado, temperamental y filosóficamente, contrario a las vastas sistematizaciones o teorías totalizantes de la historia de los hombres (Said, 2004).
} 
desde el punto de vista de los individuos, las razones del viaje, la relación entre los preceptos ideológicos del viajero en cuanto a la concepción de la sociedad visitada y la vinculación directa e indirecta con los individuos que la conforman.

2. Imaginarios e interpretaciones de la nación desde el aspecto económico y social. Pertenece a esa experiencia cotidiana de los viajeros de asimilar lo más rápida y posible la idea del entorno social visitado. En consecuencia, utilizan como mecanismo los metadiscursos basados en grandes paradigmas de la interpretación del mundo y de la sociedad de acuerdo a sus habitantes. Pero, esta visión empírica los hará caer en ideologías dogmáticas.

Finalmente, esta manera particular de ver las relaciones entre los ciudadanos, dará lugar a una reinterpretación homogeneizadora y trivial acerca de los habitantes, es decir, el conocimiento de esa supuesta realidad hará que el autor viajero la trate de traducir y transmitir al lector desde su prisma personal.

\section{EL PUNTO DE VISTA DE LOS INDIVIDUOS, LAS RAZONES DEL VIAJE}

Las perspectivas narratológicas del punto de vista en los textos de viajes decimonónicos se diferencian de un autor a otro por ciertos aspectos sobresalientes; por ejemplo, espacio, tiempo y género, además de comparar el lugar de procedencia del viajero, quien confronta sus preceptos morales y conceptos personales, colocándolos como digno ejemplo a seguir en la sociedad que visita.

A su vez, estas conceptualizaciones van a generar un segundo momento, es decir, un desdoblamiento que parte de la formación y transformación de una realidad, la cual estará acorde con la formación de distintos conceptos implícitos en el viajero.

La primera conceptualización trata sobre los puntos de vista de los individuos, ya que desde esta óptica particular dependerán todas las motivaciones viajeras del autor. Los antecedentes previos de la visita a un país extranjero son diversos y en William V. Wells el propósito del viaje se refleja como un elemento dinamizador, puesto que desde el inicio del libro informa acerca de su finalidad:

A principios de 1854 salí de San Francisco, California, para visitar Centro América con el propósito de obtener ciertas concesiones mineras y comerciales del Gobierno de Honduras... La empresa, que surgió de un comerciante de Nueva York, había pasado de mano en mano, hasta que los papeles y los documentos relacionados con la misma fueron a parar a California... Se consideraba la oportunidad como peculiarmente favorablea 
una feliz negociación con el pueblo de Centro América y especialmente con el de Honduras (Wells: 5-6).

La motivación de Wells es, en primera instancia, de índole comercial, pero también dice que:

"Al salir de California no tenía más propósito que el de informar a varios amigos de San Francisco que se habían interesado en mi empresa encaminada a conseguir del Gobierno de Honduras el derecho de explotar yacimientos de oro y de establecer estaciones comerciales para la exportación de pieles, maderas de construcción, maderas de tinte y otros objetos de valor, por el río Guayape o Patuca desde el departamento de Olancho, más al considerar lo poco conocida que, entonces, era Honduras resolví, además de cumplir con los deberes que específicamente me había trazado, dedicar parte de cada día a llevar un registro de los acontecimientos que me sucedieron y que abarcaran las peculiaridades de carácter de costumbres y las ocurrencias generales del viaje en medio de un pueblo aislado y primitivo..." (Wells: iii-iv).

A través de estas palabras el autor va perfilando su entera manifestación de recrear en su escrito una mezcla de manifestaciones y expresiones de lo observado y vivido a través de la aventura viajera que vive en el día a día mediante la geografía y la diversidad natural y de ambientes del país que visita, tal como lo afirma Mary Pratt (1992:63), quien habla de la sistematización que se puede percibir en los propósitos del viaje: "...El surgimiento de la explotación interior, el relevo cartográfico sistemático de la superficie del globo, se correlaciona con una amplia búsqueda de mercados, recursos comercialmente explotable y tierras para colonizar".

A continuación se presenta un ejemplo de lo anterior en la narrativa de Wells:

"Con esta mira, durante mi viaje de cerca de un año, que se extendió a más de mil millas, la mayor parte a lomo de mula y visitando en ese lapso treinta y ocho ciudades y aldeas, reuní todo cuanto me pareció a propósito para arrojar luz sobre la historia y recursos naturales del país. Monedas, retratos, muestras botánicas, mineralogía y ornitológicas, folletos de toda clase, publicaciones durante cincuenta años en la prensa local, viejos libros, gacetas, diarios y manuscritos y una serie de dibujos ejecutados por el señor Lazo, de 
Tegucigalpa que me acompañó a Olancho, me permitieron al regreso reunir hechos suficientes para merecer su incorporación en la forma de libro impreso. Se me extraviaron algunos de mis retratos, mapas y vistas de paisajes más importantes, que no podrán reemplazar con exactitud" (Wells: iv-v).

Esta motivación remite a una consideración y categorización del viaje a través de diferentes manifestaciones, tales como la ubicación geográfica del país visitado, el clima, la naturaleza, los caminos, los poblados, los paisajes, la gente, las costumbres, entre otros.

Al leer estas motivaciones viajeras el contraste de diferencias es complejo, ya que por medio de estas diversidades se reconocen distintas motivaciones del autor, que va desde su procedencia, estatus social, momento del viaje, género, recorrido territorial, desarrollo del periplo y además un propósito principal, que en el caso de Wells es de índole estrictamente comercial y político. ${ }^{5}$

\section{La concepción de la sociedad visitada}

La visión que se tiene por parte de los viajeros de la sociedad visitada responderá a la comprensión de un sinnúmero de fenómenos observados, es decir, a cierta visión fundamentada generalmente en una serie de prejuicios que no constituyen el conocimiento auténtico de la sociedad que visitan y sobre los espacios de los que se apropian de forma incómoda por medio de una gran cantidad de imágenes, que no solo son limitadas y esnobistas, sino también distorsionadas.

En el modelo de la literatura de viaje, concebir la sociedad visitada equivale a reinterpretar, o sea, que la mirada inquisidora del viajero observa, interpreta, revaloriza y crítica; aunque no es absolutamente necesario hacer que la realidad vista se relacione con la que existe, se percibe o se describe. Esto se refiere a la noción humana de creer que una realidad pasa siempre por la lente y la distancia dicotómica, aquella que se basa en la relación asimétrica que hay entre ver e interpretar. Esta lente de cristal posee un filtro intermedio y subjetivo, relacionado

\footnotetext{
${ }^{5}$ Wells al iniciar su relato de viaje de inmediato introduce el único propósito "El viaje, del cual las páginas siguientes forman un diario complementado después con datos reunidos en Honduras, fue concebido en California en 1853 y basado en información, digna de confianza, que desde 1851 había sido puesta en mis manos, referente a las regiones auríferas de Centro América. Su principal objeto era llevar a cabo un reconocimiento en la parte de la República de Honduras conocida como Olancho, que en 1850 había sido visitada por un ciudadano que ahora reside en Nueva York y que, según él, era otra "California" igualando al nuevo El Dorado en depósitos auríferos y aventajándolo en posición y accesibilidad y que el Gobierno de Honduras había manifestado su disposición favorable hacia las empresas extranjeras..." (1982: I-II).
} 
de forma directa, por ejemplo, con la procedencia del viajero-autor, de la ideología personal, del género y en particular del espacio recorrido y del tiempo del viaje.

Según la definición en el diccionario de la RAE (2007: 397) de interpretar, esta se define como explicar o declarar el sentido de algo y principalmente el de un texto; traducir de una lengua a otra, sobre todo cuando se hace oralmente; explicar acciones, dichos o sucesos que pueden ser entendidos de diferentes modos; y concebir, ordenar o expresar de un modo personal la realidad. Pero, también interpretar es conjeturar y el escritor viajero responde a esta interpretación como el único método de validación al momento de describir la cultura hondureña, aproximando su lógica descriptiva hasta cierto punto perceptible en el discurso escrito.

De esta forma, cada argumentación va acompañada de una lógica personal cualitativa y cuantitativa. Esta reinterpretación es eminentemente subjetiva y va a crear un serio conflicto entre el texto mostrado y la valoración de la realidad. Y es que el argumento escritural es una mera referencia a través de un lenguaje configurado en palabras.

Sobre esta problemática de la interpretación cultural, Cliffort Geertz (1990) señala que para describir y analizar una cultura, primero se deben desentrañar todas las estructuras de significación; es decir, conocer sus códigos, el campo social, discernir y descifrar el contexto, distinguiendo las diferentes estructuras y después de hacer todo esto, sigue conocer la razón y el porqué de la actuación de los individuos en esa cultura particular:

La cultura es un documento activo, es pues pública. Aunque contiene ideas, la cultura no existe en la cabeza de alguien; aunque no es física, no es una entidad oculta. El interminable debate en el seno de la antropología sobre si la cultura es 'subjetiva' u 'objetiva' junto con el intercambio recíproco de insultos intelectuales ('idealista','mentalista',' conductista', 'impresionista', 'positivista') que lo acompaña, está por entero mal planteada. Una vez que la conducta humana es vista como acción simbólica -acción que, lo mismo que la fonación en el habla, el color en la pintura, las líneas en la escritura o el sonido en la música significa algo- pierde sentido la cuestión de saber si la cultura es conducta estructurada o una estructura de la mente 0 hasta las dos cosas juntas mezcladas (Geertz, 1982: 20-21).

En conclusión, en los viajes, interpretar es tener una copresencia en el lugar, 
conocer la historia de la sociedad y saber de todas las relaciones sociales, ya que la literatura de viajes no solo se trata de describir, sino también de traducir, de interpretar la realidad visitada y esto únicamente es posible al observar, conversar, tratar a los individuos, establecer relaciones, conocer la rutina, las costumbres; en sí, es conocer cada parte de ese universo cultural. Al respecto, Paul Ricoeur (2004:17) indica que "un mensaje es intencional, es pensado por alguien, es arbitrario y contingente", por lo cual dentro del texto viajero de Wells se desarrolla una descripción de la sociedad hondureña basada en un mensaje narrativo, reflejado por medio de la intencionalidad, positiva o negativa, del autor.

Esa aprehensión de la cultura solamente es una simple aproximación finita que parte de un criterio individual, hacia el postulado de una realidad, pero que difícilmente se acerca a la realidad concreta. La posición del autor se da en tratar de representar las entidades culturales, en particular fundamentado en su apreciación, al utilizar el método comparativo de los entes, es así que el autor debe conocer primero las personas, la culturas y los espacios sociales, combinando esta comparación con cada uno de los hechos observados.

Estas descripciones viajeras tienen un significado propio y cerrado, definido por la relación puramente externa que se da entre el sujeto visitante y los sujetos visitados. Por ejemplo, hablando de los significados en el siglo XIX, resalta que en todos los libros de viajes se debe considerar la procedencia del autor, pues incide de forma directa si este tiene raíces norteamericanas o europeas, mujer u hombre, puesto que en los constructos literarios viajeros se van a erigir en discursos descriptivos muy sui géneris conforme a lo que puede representar la figura del viajero.

Cada autor construye el relato basándose en criterios específicos caracterizados por aspectos relevantes como el pensamiento ideológico, la sociedad de donde viene, de la formación académica y de la experiencia viajera. Así, la descripción de la sociedad hondureña aparece en el texto de Wells como la de un mundo muy particular, con un sinnúmero de interacciones, de oposiciones, de diferencias constitutivas, es decir, la sociedad hondureña decimonónica propuesta en este libro se muestra unidimensional en una constante oposición a ese "yo" representado en la figura de Wells. A pesar de que el periplo se da en distintas entidades sociales y culturales hondureñas, la descripción "wellsiana" es una construcción sintética reductible, negativa, presentando la realidad como una invención y una reconstrucción de las apariencias y de las experiencias del viaje.

Todas estas perspectivas de la concepción de la sociedad se basan en la descripción de la supuesta realidad y, al mismo tiempo, en la interpretación de esta 
aplicada a la sociedad hondureña. Criterios muy subjetivos son instaurados y aplicados y además validados por Wells, pero en definitiva, se considera que estas concepciones son muy particulares y esnobistas, tal como se puede apreciar en la siguiente cita:

Los habitantes aparte de los miembros dignos y en extremo corteses de las viejas y ricas familias, muestran una extraña combinación de urbanidad, sencillez, sutileza y desfachatez y, sobre todo, una indescriptible indiferencia en sus rostros, que confunde al extranjero hasta que a este, por fuerza de la costumbre, se le hace familiar, se paran a espiar dentro de las ventanas para escudriñar a uno en el acto de vestirse, y al encontrarse con los ojos de uno, se vuelven y hacen una reverencia digna de un Chesterfield; ponen sus hogares y todo lo de ellos a nuestra disposición, pero están prestos a redondear al siguiente día cualquier negocio leonino a costillas de uno y así hasta el fin. Como todos los españoles 0 mestizos españoles, son grandes tahúres... Estos les viene de sus ancestros; y en relación con los hábitos de pereza en un gran sector de la clase media..." (Wells: 175-176).

La cita anterior aplica a lo que se denominó como la visión instruida del viajero, pues el norteamericano transmite esa mirada del mundo a través de su "ojo instruido masculino que sostenía un sistema que podía familiarizar (naturalizar) los nuevos sitios- vistas inmediatamente y por contacto al incorporarlos al sistema del lenguaje" (Pratt, 1992:64).

Esta narración de Wells conduce a una serie de particularidades al tratar de hacer un análisis de los fenómenos sociales significativos que dan cuenta de esa visión subjetiva humana que persiste en la óptica de este viajero decimonónico, al irrumpir en los diferentes estratos sociales hondureños.

Así, a partir del análisis de esa visión subjetiva, se observa que Wells muestra los fenómenos sociales como simples fenómenos de significación, por ejemplo el caso donde manifiesta que: "el hondureño es un haragán, ${ }^{6}$ es tahúr y esto ha sido

\footnotetext{
${ }^{6}$ Esa marca de holgazanería y pereza también es impuesta a las descripciones de los hondureños desde una mirada viajera a ciertos individuos dentro de la sociedad hondureña, misma que es señalada por el alemán Jegór Von Sivers, quien en el libro A través de Madeira, las Antillas y Centro América. Memorias de viaje e investigaciones, publicado en 1861, dice: "Aquí en la costa es bastante numeroso el grupo de los criollos superando a estos el grupo de los llamados negros, quienes se destacan de los demás grupos respecto a la comprensión y al talento, pero lástima que son los más inútiles". (Yaxkin, 2009).

${ }^{7}$ Ídem.
} 
heredado por los colonizadores españoles". ${ }^{7}$ Estas frases despectivas serán de uso común a lo largo del escrito, ya que el norteamericano utiliza este lenguaje como medio privilegiado del valor semántico de las palabras, para describir subjetivamente a la sociedad visitada.

Desde el punto de vista personal del autor, es posible percibir que solo él posee un relativo conocimiento social y una pobre comprensión de la sociedad que apenas viene conociendo. Sus palabras no logran transmitir de forma directa y clara la realidad, sino que únicamente lo hace a partir de mediaciones y de expresiones subjetivas, denominadas por Pratt como "resemantización" global (1992:64).

En este sentido, se puede señalar que los sujetos sociales no se dan a conocer por sí mismos directamente, sino que se presentan al lector por medio de signos transfigurados en la memoria, el recuerdo y las palabras, convenciones generadas por aquellos imaginarios que el escritor se apropia y particulariza acerca de la cultura que de buena forma lo acogió dignamente.

Estos señalamientos injustos hacia los hondureños, de los que hace acopio Wells, son el producto de errores de apreciación. Al respecto, las palabras de Amy Gutman (2008:9) señalan y plantean diversas disyuntivas sobre el hecho, de un error de apreciación que puede tener un viajero al tomar grupos identitarios como única fuente para asignarle un valor colectivo:

...Cuando se identifica a las personas en términos de blanco 0 negro, varón o mujer, irlandés o árabe, católico o judío, sordo o mudo, se recurre a estereotipos de raza, género, ascendencia étnica, religión o discapacidad y se les niega la individualidad que resulta de su propio carácter distintivo y de la libertad de adhesión según su voluntad. Cuando los individuos mismos, a causa de haber sido identificados con cierto grupo, se reconocen por su raza, ascendencia étnica o religión, suelen generarse actitudes hostiles hacia otros grupos y un sentimiento de superioridad sobre los demás. Con frecuencia, los grupos rivalizan unos con otros sin concesiones y sacrifican la justicia e incluso la paz con tal de reivindicar su superioridad como grupo.

Los viajeros no pueden señalar una igualdad de sujetos sociales, peor aún en cuestiones de grupos identitarios. En Exploraciones y Aventuras en Honduras, Wells se da a la tarea de fomentar estereotipos ${ }^{8}$ que por lo general son negativos, además peca al tratar de incitar al lector a considerar el fenómeno cultural a través

${ }^{7}$ Ídem. 
de marcadores sociales muy individuales; por ejemplo, Wells condiciona a todos los hondureños como tahúres, haraganes, ociosos, vagabundos, lisonjeros; en vez de reconocer que más allá de ciertos aspectos sociales adversos, existen otros talentos positivos. Igualmente, este autor identifica la holgazanería con la procedencia geográfica del sujeto: "es tan haragán como un olanchano" (Wells: 348). De hecho, en esta frase seguimos percibiendo los estereotipos de carácter particular, bastantes frecuentados por el autor, al describir a cada habitante de Honduras.

En la actualidad es posible reconocer el hecho de que "la traducción cultural" se pregunte cómo se puede comprender la cultura, pero en el siglo XIX era imposible hacerse esta interrogante, puesto que las ideas de los viajeros al tratar de traducir la cultura se fundamentaban tan solo en el hecho del conocimiento mediado y apropiado desde el punto de vista estrictamente personal. Siempre, estos enfoques del autor observador, tenían su base en conceptos e indicios referenciales vistos desde el propio caleidoscopio cultural, por el cual va a traducir y clasificar la realidad de los otros, que son los visitados.

En su momento, Gertz (1990: 23) plantea y explica estas interpretaciones expresadas en los escritos viajeros que describen una cultura: "este hecho que lo que nosotros llamamos datos son realmente interpretaciones de otras personas de lo que ellas piensan y sienten". La siguiente cita de Wells confirma lo que Gertz sostiene:

Fastidiado de tanto andar a caballo, desfallecido por el agotamiento y el hambre, usted se desmonta y después de saltar los charcos y zanjas, busca a tientas la entrada de la choza más grande entre una colección de ahumadas barracas de adobe, que más parecen moradas de hotentotes que de seres semicivilizados. Usted se contiene de no abrir la puerta, recordando a los perros, ante cuyos colmillos ni las botas, ni las sobrebotas son suficientes. Entonces usted grita en un argentino castellano, rogando ser admitido y la respuesta es un gruñido. Si usted agrega un aliciente pecuniario en un castellano más elocuente, la respuesta es una algaraza de chiquillos que chillan en coro y el regaño de la señora despertando a

\footnotetext{
${ }^{8}$ Acerca de los estereotipos con referencia a lo haragán en los iberoamericanos, llama la atención lo que dice Jean Plumyene al respecto de la pereza española en el libro Catálogo de necedades que los europeos se aplican mutuamente: "Hay unanimidad en Europa. Los españoles son perezosos... pues el pueblo español nunca se siente tentado por el trabajo, a menos que concurra una necesidad irresistible, ya que no descubre ventaja alguna de la industria... El misticismo y el instinto de gozar, que constituyen el fondo del carácter español, se ponen de acuerdo para fomentar la inactividad en España, tanto a base de contemplación como de despreocupación, o de ir pasando de una a otra (la alternancia, fenómeno profundamente español). Todo su ser, es decir, su instinto sostenido por su razón, le dice que ahí está el bien soberano y que, por lo demás, 'la vida es sueño"' (1973:61-62).
} 
su compañero dormilón, a quien ordena abrir la puerta a los extraños... Por fin la puerta se abre y usted obtiene permiso para poder ocupar el suelo por la noche o tal vez para colgar la hamaca de las vigas (1982: 227).

La cita que se presenta a continuación es un pasaje de Wells en donde el autor observa y clasifica cierto hecho ocurrido en la sociedad de Honduras, desde su propia y particular óptica cultural:

El sistema de mezclar las sangres se ha introducido en Honduras durante los últimos treinta años, casi ha borrado la línea divisoria entre los blancos y los negros. Esto es, quizás, la mayor desgracia que ha podido sobrevenirle al país. La mezcla de los vástagos del negro, del blanco y del indio ha perpetuado en esa república una raza que recorre la gama de colores del chocolate a la crema. Se puede ver en raras ocasiones un blanco entre los descendientes de las viejas familias aristocráticas de España que, celosamente, han evitado matrimonio con indios o con negros, pero en estos casos excepcionales y con el actual aumento numérico de las otras razas, pareciera que se contempla la exterminación eventual de la raza caucásica con un resignado desaliento (1982: 169).

Dentro de este pasaje de Wells, la palabra clave es raza, como una definición particular basada en un sentimiento encontrado que parte desde la superioridad racial, hasta llegar a las sensaciones e intuiciones; pero, en todo caso, la explicación particular del abstracto racista y despectivo, donde el mismo Wells opina que la mezcla interracial ${ }^{9}$ conlleva sin lugar a dudas a la "terminación eventual de la raza caucásica".

\footnotetext{
${ }^{9}$ Pedro Yurita (1967: 107-110), en el artículo Nomenclatura etnográfica popular durante a la colonia, aporta sobre la fusión de las razas indígenas y españolas que dio inicio al mestizaje:

1. Blanco 2. India Mestizo 1 parte sangre blanca

$=$ Mestizo

Casta de ladinos 1. Blanca 2. Blanca
$=$ Blanco

Casta criollos

1. Blanca 2. Blanca $=$ Blanco

1 parte sangre india

2 partes

Ladina 3 partes sangre blanca

1 parte sangre india

4 partes 3. Blanco 4. Blanca
$=$ Blanco

5. Blanco 6. Indio
$=$ Mestizo

Criolla

7. Blanco 8. Mestizo $=$ Ladino

7 partes sangre blanca 1 parte sangre india

8 partes
} 
En su momento, Wells pareciera que estuviese reaccionando a lo que Walter Connor (2009: 6), en el texto el Caos terminológico, indica cómo: "Pensar con la sangre... un modo semejante de activar una vibración psicológica fundada implícitamente en la idea de esa raza superior que en una nebulosa época protohistórica existieron un Adán y una Eva -alemanes- y que la descendencia de esta pareja ha evolucionado hasta nuestros días prácticamente sin adulterarse".

Ahora bien, después de llamar la atención sobre este vínculo expresado por Wells en torno a las múltiples y estereotipadas mezclas raciales en Honduras, también se pueden apreciar todos los términos despectivos que dirige el anglosajón al lector, por medio de un tono intimista y además muy peyorativo hacia la raza hondureña.

Este viajero hace explícita su intención, pues no solo describe, sino que explica lo que observa, basando todas las interpretaciones en sus propias convenciones y convicciones religiosas y morales. Este punto de vista se muestra en todo el relato viajero, su escritura se caracteriza por la enorme profusión de apreciaciones racistas, además de otras situaciones sórdidas que narra y explica, todo con base al componente racial de los individuos involucrados en esas situaciones, obviando Wells el contexto sociocultural en que ocurren estas escenas humanas.

Sin embargo, estas incisivas reflexiones permiten un acercamiento a las ideas del momento de esta época decimonónica, dentro de los imagotipos ${ }^{10}$ que se tienen en ese periodo histórico de los centroamericanos. Estos son elaborados como el producto de una interpretación categórica, basada en superioridad social y etnocentrista anglosajona, producto de los procesos históricos, políticos y sociales de los Estados Unidos, propios de esa época del año de 1854. Tales procesos dejarán una marca colonialista que influenciará notablemente a William Wells, quien presenta al lector de la época un postulado racista al expresar que en estas tierras tropicales se producía una subcultura con relación a la cultura estadounidense, manifestando también que la sociedad hondureña es imperfecta, conformada por hombres y mujeres de calidad inferior.

${ }^{10}$ Esta palabra está aplicada a la literatura viajera decimonónica centroamericana, utilizada por Christina Schramm en el ensayo Colocando América en el mundo. Mirada, miradas y narraciones. El ejemplo de Wilhelm Marr: Viaje a Centroamérica, en este Schramm dice: "Parto de dos tipos fundamentales de imágenes utilizadas por Marr como punto de referencia al escribir su libro de viaje. El primero trata del imagotipo de la naturaleza como grandiosa y fantástica por un lado y la naturaleza como fatigante y peligrosa por el otro lado. El segundo imagotipo, relacionado con el primero, trata de la supuesta inferioridad de los americanos frente los europeos. Con ello hago referencia a la clasificación de imagotipos retomada y ampliada por el autor Werner Mackenbach (1998: 158), quien se basa en la autora Marlene Rall. Esta última distingue diez imagotipos en la literatura de lengua alemana desde la conquista. Cabe resaltar, que el término "imagotipo" se refiere a "las imágenes en nuestras cabezas", es decir, a los "estereotipos, mentalidades, prejuicios, valores, ideas fijas [0] actitudes" Christina Schramm (Istmo, 14, 2007). 
En resumen, los fragmentos textuales presentados dejan expuesta la conjetura sobre la "dimensión fragmentaria", que desde la perspectiva antropológica se define como la expresión de contacto entre el «yo» superior y los «otros» inferiores; del tal modo que los textos narrativos de Wells son trazos informativos que manifiestan un cierto nivel de comparación cualitativo, cuantitativo, informal y empírico.

\section{CONSIDERACIONES FINALES}

En este libro de literatura viajera se observa que el escritor actúa como un crítico colonial o un intelectual "de frontera", mismo que parece navegar en el espacio del "otro" visitado, posicionando al país visitado entre el más marginal en comparación al país de procedencia.

En los espacios de los discursos de las identidades, propiamente las encontradas en el texto, se producen algunos limitados efectos de demostración, pues no es posible apreciar la verificación de una realidad integrada, es decir, que William V. Wells hace muchas veces distintas reflexiones como crítico de lo que mira, pero con una visión miope y muy complaciente, con relación a esos ojos extranjeros que hacen de cada una de sus palabras una seductora parábola.

El viajero narra por medio de su único punto de vista, el personal. Por lo general, estas referencias escriturales están muy alejadas de la realidad de la Honduras del siglo XIX; lo cual se puede apreciar si hacemos una lectura filológica del libro. Al mismo tiempo, se puede observar la relación que existe entre los discursos del viajero con un alto grado de connotación nacionalista, racista y egocéntrica; y los discursos textuales que desbordan una crítica sórdida, en especial, cuando hace referencias sobre género, etnicidad y comportamiento sociocultural.

Al respecto, se debe recordar que, históricamente, a mediados del siglo XIX, Honduras está pasando una época de transiciones, la posindependista, seguida por el corto período del sueño confederativo y, por último, precisamente por esos años del periplo de Wells, la nación se encuentra en la búsqueda constante de sentar las bases económica y sociales para consolidar un gobierno republicano.

\section{AGRADECIMIENTOS}

A la Dirección de Investigación Científica y Posgrado de la UNAH, en especial a su directora, Leticia Salomón, y a su grupo de trabajo por auspiciar la beca de investigación para la tesis. 
También mi gratitud al Dr. Luis Alburquerque del Consejo Superior de Investigaciones Científicas, CSIC, España, quien impulsó mi espíritu investigador hacia la literatura de viajes y quien ha dedicado horas de trabajo en la asesoría de la tesis.

\section{BIBLIOGRAFÍA}

Acuña Ortega, Víctor Hugo. (2009). Etnicidad y nación: los debates actuales en las ciencias sociales. Managua: IHNCA.

Alburquerque, Luis. (2005). Consideraciones acerca del género relato de viajes en la literatura del siglo de oro. En Mata, Carlos y Sagasti, Miguel (Eds me equivoqué al colocar des). Actas del congreso: El siglo oro en el nuevo milenio. Pamplona: Eunsa.

Alburquerque, Luis. (2006). Los libros de viaje como género literario. En Estudios de la literatura de viajes. Madrid: CSIC (en prensa).

Barahona, Miguel. (2006). La búsqueda y construcción de la identidad: Los viajes de Hernán Cortés y William V. Wells a Honduras. Madrid: Tesis CSIC.

Barahona, Miguel. (2013). A propósito del viaje. Analogía y subjetividad en Exploraciones y Aventuras en Honduras de William Vincent Wells. Istmo, 14. Recuperado de: http://istmo.denison.edu/n14/articulos/viaje.html

Carrizo Rueda, Sofía. (1997). Poética del relato de viajes. México: Kassel, Edition Reichenberger.

Champeau, Geniève. (2004). El relato de viaje, un género fronterizo. Madrid: Verbum.

Connor, Walter. (2009). Etnonacionalismo. El caos terminológico. Managua. Recuperado de:

http://catarina.udlap.mx/u_dl_a/tales/documentos/lri/cruz_f_c/capitulo1.pdf

Gutmann, A. (2008). Lo bueno, lo malo y lo feo de la política basada en la identidad. La identidad en democracia. Argentina: Katz.

Gannier, Odile. (2001). Litteérature de voyage. París: Ellipsis.

Geertz, Clidfford. (1990). La interpretación de las culturas. Barcelona: Gedisa.

Gómez Arboleda, Enrique. (1952). Breve meditación sobre el viaje. Madrid: Instituto de Cultura Hispánica.

Mignolo, Walter por favor quitar la D(2008). La opción descolonial. Desprendimiento y apertura. Un manifiesto y un caso. Revista de Humanidades 8,243-281. Bogotá.

Péñate Rivero, Julio. (2004). Relatos de viaje y literatura hispánicas. Madrid: Visor Libros.

Pérez Brignoli, Héctor. (1990). Breve Historia de Centroamérica. Madrid: Alianza Editorial.

Porter, Dennis. (1993). Modernism and the Dream of Travel. Literature and Travel. Amsterdam: Rodopi. 
Pratt, Mary Louise. (1992). Imperial Eyes. New York: Routledge.

Pratt, Mary Louise. (1992). Ojos imperiales. Literatura de viajes y transculturización. Buenos Aires: Editorial Universidad de Quilmes.

Pratt, Mary Louise. (1990). Woman, literature and National Brotherhood. Women, Culture, and Politics in Latin America. Berkeley and Los Angeles: University of California.

Plumyene, Jean. (1973). Catálogo de necedades que los europeos se aplican mutuamente. Barcelona: Barral.

Ricoeur, Paul. (2001). Teoría de la interpretación, discurso y excedente de sentido. México: Siglo XXI.

Said, Edward W. (2004). Cultura e imperialismo. Barcelona: Editorial Anagrama.

Sivers, Jegór von. (2009). A través de Madeira, las Antillas y Centro América. Memorias de viaje e investigaciones. Yaxkin, (XXV)1, 131-162, Tegucigalpa.

Wells, William. (1982). Exploraciones y aventuras en Honduras. Costa Rica: Educa.

Yurrita Maury, Pedro. (1967). Nomenclatura etnográfica popular durante la colonia. Revista de la Academia Guatemalteca de Estudios Genealógicos, Heráldicos e Históricos, 1,109-110, Guatemala.

Zepeda, Ismael. (2008). Honduras y las relaciones internacionales (1850-1900). Los laberintos de los empréstitos del ferrocarril y las consecuencias de endeudamiento y corrupción. Revista Estudios, 21, Universidad de Costa Rica. 